\title{
Finger systolic pressure: its use in screening for hypertension and monitoring
}

\author{
ALAN CLOSE, GUY HAMILTON, SUSAN MURISS
}

\begin{abstract}
A finger sphygmomanometer was compared with a mercury column sphygmomanometer for its ability to screen for hypertension. A total of 881 patients used each machine, both in initial screening and then for monitoring. The finger sphygmomanometer had a specificity of $98.5 \%$ in routine screening as compared with $\mathbf{9 7 . 6 \%}$ for the mercury column device. Sensitivity of the finger device was $98 \cdot 2 \%$.

These findings suggest that the finger sphygmomanometer using finger systolic pressure alone is adequate for screening and monitoring blood pressure.
\end{abstract}

\section{Introduction}

Cardiovascular morbidity and mortality are lowest in those who are normotensive-for example, a man of 35 who has a blood pressure of $140 / 90 \mathrm{~mm} \mathrm{Hg}$ has a life expectancy of 41.5 years, whereas if his blood pressure is $150 / 100 \mathrm{~mm} \mathrm{Hg}$ his expectancy is only 25 years.' Adequate blood pressure screening to pick up the hypertensive as early as possible is therefore an essential part of modern health care.

In Britain fewer than half of people with hypertension are thought to be detected by a combination of screening, ${ }^{2}$ opportunistic screening, ${ }^{3}$ and case finding ${ }^{4}$ examinations in the general practitioner's surgery. ${ }^{5}$ Moreover, of those who are detected, fewer than half receive the required treatment and follow up care, including having their blood pressure monitored during treatment. Part of this problem may be due to the time it takes to measure blood pressure conventionally and to the reluctance of patients to undress for the procedure unless strongly motivated. We estimate that in our health centre a standard surgery of 20 patients would take an extra

St John's Health Centre, Woking, Surrey GU21 1TD

ALAN CLOSE, MD, general practitioner

GUY HAMILTON, MB, BS, general practitioner

SUSAN MURISS, SRN, hypertension screening nurse

Correspondence to: Dr Close.
30 minutes if each patient's blood pressure was measured as a separate item of service.

In the United States pay booths for measuring blood pressure have proved unsuccessful because of fear and the need to undress and are gradually being withdrawn from public areas and pharmacies. By contrast, pay booth pulse meters are quite acceptable, requiring only insertion of the finger. We thought that the uptake of screening might be improved if a "hole in the wall" device was available in clinics in Britain. Receptionists might carry out the screening while registering the patient or the doctor might do this while taking a history or carrying out other procedures. Furthermore, the ease of use of such a machine might facilitate home monitoring or follow up by paramedical workers.

We therefore decided to assess the accuracy and convenience of a finger sphygmomanometer as a screening device in general practice. We also tested its efficiency in monitoring blood pressure in patients diagnosed as hypertensive and compared it with conventional mercury column sphygmomanometry in screening for hypertension in a given population. As our gold standard we used the Hawksley random zero sphygmomanometer, which the Medical Research Council working party chose for screening for mild hypertension. ${ }^{6}$

\section{Materials and methods}

The study was carried out in our hypertensive screening clinic during February to June 1985. The finger sphygmomanometer tested (fig 1) measures systolic pressure only, which has been suggested as the more reliable indicator for making diagnostic and therapeutic decisions. ${ }^{7-13}$

The finger sphygmomanometer (prototype of the Minimonitor; Tripod Industries, UK) comprises the following components: an inflatable finger cuff; a screw threaded piston to provide inflation; a pulse sensor; an electrical capacitor converting the sensed pulse into visual indication; and an aneroid manometer for measuring the pressure exerted in the cuff. The cuff obturates the digital artery, and after progressive inflation and deflation the pulse sensor downstream of the cuff detects a pulse. Pressure indicated by the manometer represents systolic pressure. Audiovisual displays are triggered when the pulse is sensed which may be read off the aneroid meter simultaneously. The pulse sensor acts as a volumetric transducer, detecting a change in the volume of the finger distal to the cuff when the systolic pressure exceeds cuff pressure. This detection of change in the volume is brought about by air displacement. Very accurate readings may be obtained by progressively inflating and deflating the cuff.

Everyone entering the health centre during the study period was 
encouraged to see a specially trained nurse working in a screened area separated from the waiting room. The patient sat with the arm horizontal at heart level, supported on a desk. ${ }^{14}$ Blood pressure was measured using, firstly, the finger sphygmomanometer and then the random zero machine. The finger sphygmomanometer cuff was used on any of the four fingers. In the case of the random zero machine the level of the mercury column was read to the nearest $2 \mathrm{~mm} \mathrm{Hg}$ at Korotkoff sounds 1 and 5 and at the resting zero point. The cuff measured $13.5 \times 22 \mathrm{~cm}$. A total of 881 patients were tested over the five months of the study.

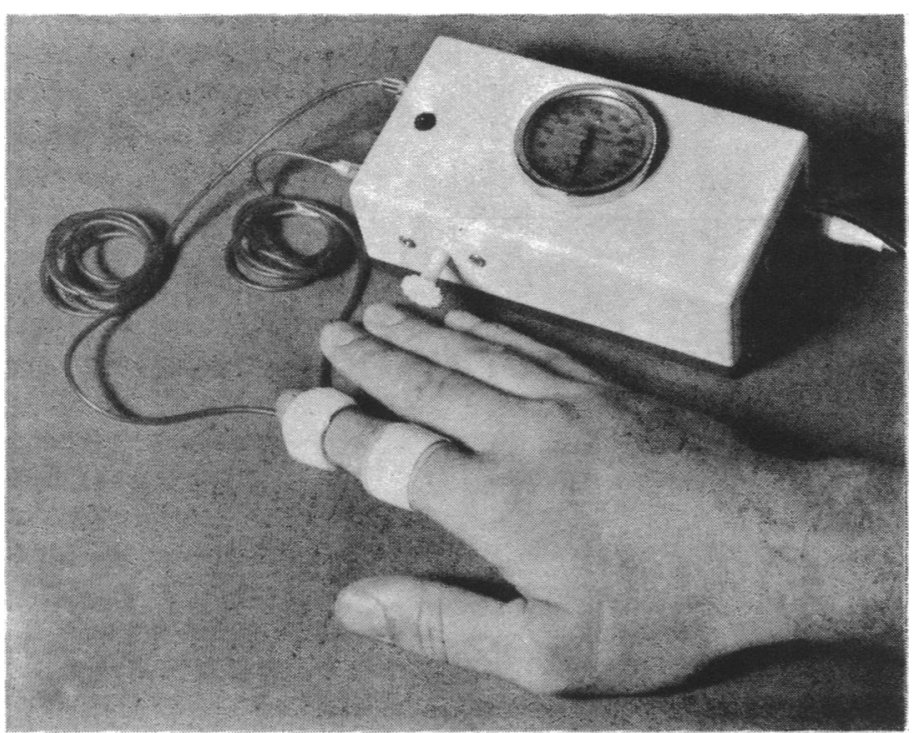

FIG 1-Finger sphygmomanometer.

Once screened, all those patients whose blood pressures were above the acceptable limit for their age and sex were monitored on three occasions over the subsequent month, both machines being used for comparison studies. Each patient positive for high blood pressure on screening was monitored for diagnostic readings and each subsequent patient similarly monitored. In monitoring for diagnostic measurements the readings were taken "blind"that is, the screening blood pressure was not known to the operator. Based on data used by the MRC Working Party on Hypertension as a baseline for age and sex norms ${ }^{15}$ all those patients whose blood pressure was still high were referred to a doctor for treatment. Subsequent monitoring of the blood pressure was carried out by the general practitioner, who also used both machines. The decision to treat or not was left to the individual doctor but was broadly based on Raftery's criteria. ${ }^{16}$

Each patient was subjected to a rigorous physical examination, chest radiography, electrocardiography, and full blood count and urea and electrolyte estimations.

Readings with the finger sphygmomanometer were taken first. The order of blood pressure measurement was not randomised and readings were sequential. "Test positives" were those patients recorded as apparently hypertensive after one screening. "True positives" were those who after monitoring were still diagnosed as hypertensive and were then referred for treatment. By monitoring in this way each patient had three further readings over the following month plus a physical examination.

\section{Results and comment}

Table I gives the overall results with the two machines. The sensitivity of our assessment was equivalent to our ability correctly to label cases. For finger sphygmomanometry this was 0.982 - that is, 55 test positives divided by 56 true positives-and for random zero sphygmomanometry 1.0 (table II). Specificity was equivalent to our ability correctly to label non-cases. For finger sphygmomanometry this was 0.985 - that is, 813 test negatives divided by 825 true negatives - and for random zero sphygmomanometry 0.976 (table II).

The inability of the random zero machine to match the finger sphygmomanometer in specificity may have arisen in several ways. Workers in Canada comparing cuff pressures with intra-arterial measurements reported finding systolic blood pressures underestimated by more than $20 \mathrm{~mm} \mathrm{Hg}$ and diastolic pressures overestimated by $30 \mathrm{~mm} \mathrm{Hg}$ or more. ${ }^{17}$ Many patients therefore have "cuff hypertension"-an apparent diastolic blood pressure greater than $100 \mathrm{~mm} \mathrm{Hg}$ but without such typical conditions as retinopathy or renal impairment. On average the errors in cuff measurements of systolic and diastolic pressures were $-5 \mathrm{~mm} \mathrm{Hg}$ and $8 \mathrm{~mm} \mathrm{Hg}$ respectively. This error correlates with an index of arterial stiffness and is increasingly relevant with age. Nine of the 19 false positive high blood pressure readings with the random zero machine (table I) were in "diastolic hypertensives."

TABLE 1-Results of blood pressure measurements by the two methods

\begin{tabular}{lccccccccc}
\hline & \multicolumn{2}{c}{ Random zero sphygmomanometry } & & \multicolumn{3}{c}{ Finger sphygmomanometry } \\
\cline { 2 - 3 } & $\begin{array}{c}\text { True } \\
\text { positive }\end{array}$ & $\begin{array}{c}\text { True } \\
\text { negative }\end{array}$ & Total & & $\begin{array}{c}\text { True } \\
\text { positive }\end{array}$ & $\begin{array}{c}\text { True } \\
\text { negative }\end{array}$ & Total \\
\hline Test positive & 56 & 19 & 75 & & 55 & 12 & 67 \\
Test negative & 0 & 806 & 806 & & 1 & 813 & 814 \\
\hline Total & 56 & 825 & 881 & & 56 & 825 & 881 \\
\hline
\end{tabular}

Cuff size is also important. Standard sized cuffs used in screening general populations may result in apparently increased blood pressure readings in overweight members. ${ }^{18}$ Cuff size seems unimportant in finger sphygmomanometry, whereas with the random zero machine inappropriate sizing gives artificially high readings. Hence in our series there were more false positive readings with conventional sphygmomanometry than with finger sphygmomanometry.

TABLE II-Sensitivity and specificity of the two methods of measurement

\begin{tabular}{lll}
\hline & Sensitivity & Specificity \\
\hline Random zero sphygmomanometry: & & \\
Systolic +diastolic & 1.0 & 0.976 \\
Systolic only & 0.928 & 0.988 \\
Diastolic only & 0.518 & 0.989 \\
Finger sphygmomanometry & 0.982 & 0.985 \\
\hline
\end{tabular}

All patients given treatment for their hypertension were monitored subsequently using both techniques. Both the doctors and the trained nurses in the health centre were using the machine by that time and the results with the two techniques compared favourably (see below).

By using the finger sphygmomanometer monitoring of blood pressure may be done by the patient at home or, more important, by the patient's companion when the patient is asleep, facilitating 24 hour monitoring. Circadian patterns of high blood pressure may then be established, which would facilitate far more accurate therapeutic control of hypertension in individual cases than at present.

Non-invasive devices to monitor blood pressure in ambulatory patients will change the scene in the management of hypertension. Data from a large series of patients convincingly suggested that blood pressure recorded in the individual ambulatory patient is a better indicator of his personal cardiovascular risk than the blood pressure measured in the surgery. ${ }^{19}$

Finally, we asked all our patients which of the two methods they preferred; all stated their preference for the finger sphygmomanometer. Random zero sphygmomanometry may be a particularly unpleasant and painful method of taking the blood pressure.

\section{COMPARISON OF MEASUREMENTS}

We attempted to establish whether a new, cheap, and quick method of measuring systolic pressure produces answers that agree with those from the established mercury column arm sphygmomanometer technique. We reject calculation of the correlation coefficient between the two methods of measurement, ${ }^{20}$ which is not a measure of agreement but a measure of association. It would be wrong to infer from a high correlation that the two methods may be used interchangeably.

In order to establish the degree of agreement between the two methods of recording systolic pressure we have gone for a simple approach. Figure 2 plots $x$ against $y$, where $x$ and $y$ are the relevant systolic pressures gained from random zero and finger sphygmomanometry respectively, and shows a 
line of equality through the data from the first 400 patients, who were tested by a single operator.

Figure 3 replots the same data. If $x$ and $y$ are the readings of systolic pressure with each of the two machines this reduces to a plot of $(x-y)$ against $((x+y) / 2)$. From this type of plot it is much easier to assess the magnitude of disagreement, spot outliers (for example, those fingers with peripheral vasoconstriction), and see any trends. There was no evidence of any tendency for the amount of variation to change with the magnitude of the measurements. Hence we conclude that readings obtained by finger sphygmomanometry and random zero sphygmomanometry were unlikely to differ by more than two standard deviations.

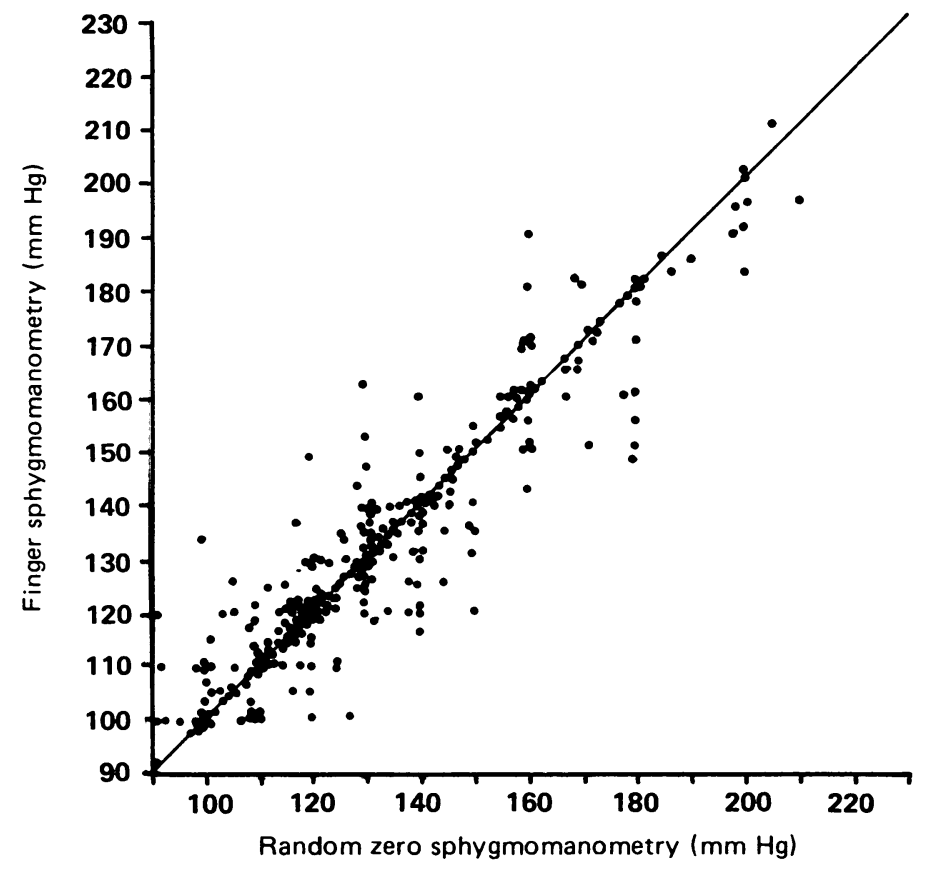

FIG 2-Comparison of systolic pressures recorded by random zero and finger sphygmomanometry in first 400 patients tested.

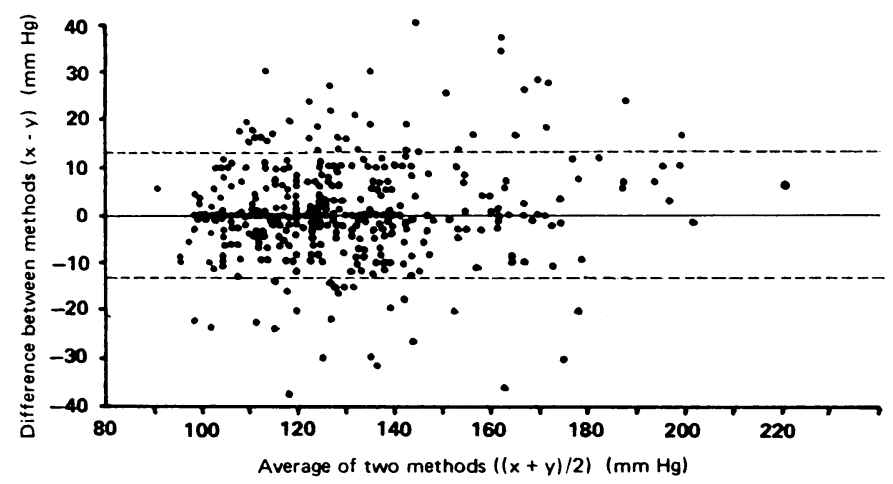

FIG 3-Reanalysis of data from figure 2. Solid and dashed lines represent line of correlation and $95 \%$ confidence interval (calculated from mean value with $2 \mathrm{SD}$ ).

Many factors may affect measurements, such as observer, time of day, position of the subject, particular instruments used, etc. There is a distinction between repeatability and reproducibility. In comparing the results obtained by the two methods the question to be answered is whether the methods are comparable to the extent that one might replace the other with sufficient accuracy for the intended purpose of measurement. For this purpose it is customary to allow results to fall within twice the standard deviation error band. ${ }^{21}$ Figure 4 presents the data from figure 3 replotted to show error and bias. Yelderman and Raem compared intra-arterial pressures with Dinamap pressures and found an error band of $17 \% .{ }^{22}$ Van Bergan showed that auscultation gives an error band of $20 \% .{ }^{23}$ The World Health Organisation acknowledges and accepts the variations of $33 \mathrm{~mm} \mathrm{Hg}$ for systolic pressure and $10 \mathrm{~mm} \mathrm{Hg}$ for diastolic pressure over 24 hours. ${ }^{24}$

\section{PROS AND CONS OF FINGER SPHYGMOMANOMETRY}

It is important to ensure that the finger is kept approximately at heart level for the test, a difference of $13.5 \mathrm{~mm}$ producing an error of about $1 \mathrm{~mm} \mathrm{Hg}$. There was no difference in recordings with variation in skin colour.

In winter some patients coming straight off the street were profoundly vasoconstricted, with skin temperatures as low as $21^{\circ} \mathrm{C}$. These fingers gave no readings initially until they were warmed (by placing the hand in a bicycle glove until the skin temperature rose), readings from a few of these appearing as outliers in figure 3 and far from the line of direct correlation. Table III gives a breakdown of all those patients whose skin temperature fell below $29^{\circ} \mathrm{C}$ through cold or Raynaud's phenomenon. Table III also includes patients who were vasoconstricted by $\beta$ blockers.

TABLE III-Analysis of patients tested by finger sphygmomanometry whose skin temperatures were below $29^{\circ} \mathrm{C}$ or who were taking $\beta$ blockers

\begin{tabular}{lcccc}
\hline & $\begin{array}{c}\text { No } \\
\text { of } \\
\text { patients }\end{array}$ & $\begin{array}{c}\text { Blood pressure } \\
\text { correlation } \\
<2 \times \mathrm{SD}\end{array}$ & $\begin{array}{c}\text { After } \\
\text { warming } \\
<2 \times \mathrm{SD}\end{array}$ & $\begin{array}{c}\text { Blood pressure } \\
\text { correlation }>2 \times \mathrm{SD} \\
\text { despite warming }\end{array}$ \\
\hline $\begin{array}{l}\text { Skin temperature }<29^{\circ} \mathrm{C} \\
\text { Receiving } \beta \text { blockers }\end{array}$ & 79 & 49 & 10 & 20 \\
$\begin{array}{l}\text { Vasoconstricted and } \\
\text { receiving } \beta \text { blockers }\end{array}$ & 4 & 35 & 3 & 1 \\
\hline
\end{tabular}

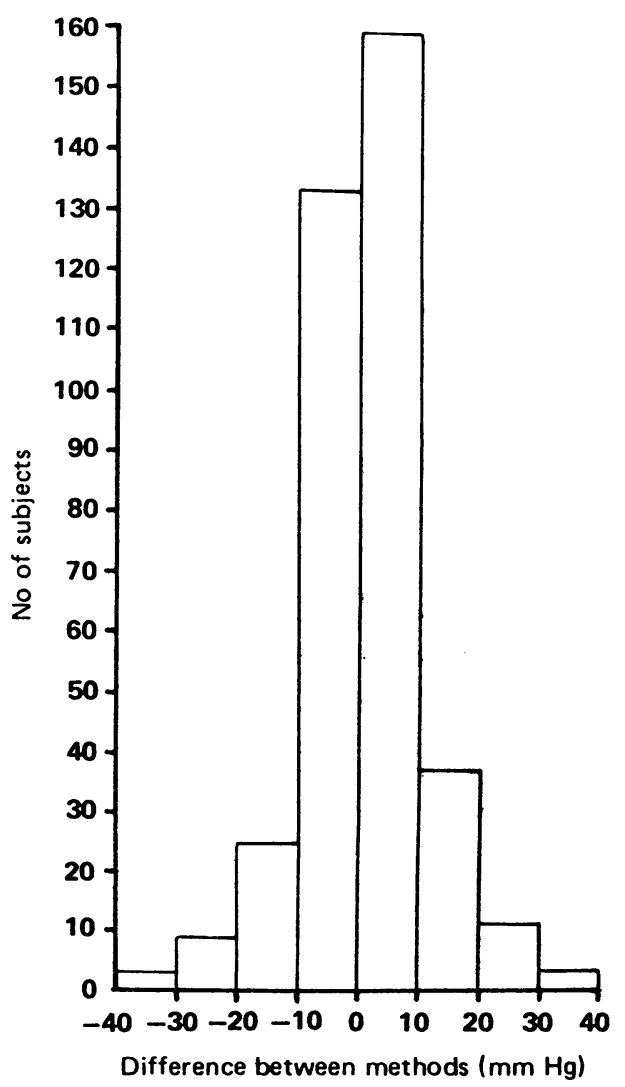

FIG 4-Data from figure 3 replotted to show error and bias.

Patients do not need to undress for finger sphygmomanometry and therefore the investigation is not unduly time consuming. The device is comfortable, portable, and gives very precise readings. It also lends itself readily to 24 hour monitoring. In addition, we found that we could use the same sized finger cuff on children. (We monitored children aged over 8 and adolescents for the duration of the trial but the results are not included in this paper.)

\section{Conclusion}

Ambulatory systolic blood pressure is an increasingly important criterion for making decisions, both diagnostically and thera- 
peutically. ${ }^{7-13}$ Because it is so convenient to use the finger sphygmomanometer is ideally suited for this measurement. Our trial shows that as a screening device the finger sphygmomanometer is more specific than the conventional mercury column device. Comparison studies between the two methods show a favourable degree of correlation. We suggest that this simple finger sphygmomanometer, using systolic pressure only, may readily be used for screening for hypertension and monitoring either at home or in the surgery.

We thank the South West Thames Regional Health Authority for help in financing the trial.

\section{References}

1 Society of Actuaries. Report on blood pressure data. USA: Society of Actuaries, 1959

2 Hart JT. The management of high blood pressure in general practice. $\mathcal{J} R$ Coll Gen Pract 1975;25:160-92.

3 Hall JA. Audit screening for hypertension in general practice. 3 R Coll Gen Pract 1985;35:243.

4 Michael G. Quality of care in managing hypertension by case finding in north west London. $\mathrm{Br}$ Med I 1984;288:906-8

5 Patterson HR. The management of hypertension in general practice. Final report. Pt II. Sheffield: Trent Regional Health Authority, 1983:5.

6 Hackett GI. Computerised self measurement of blood pressure. Practitioner 1984;228:591-3.

7 Lichtenstein MJ, Shipley MJ, Rose G. Systolic and diastolic blood pressures as predictors of coronary heart disease mortality in the Whitehall study. Br Med f 1985;291:243-5.
8 Stone $M C$. The influence of age, sex and other risk factors in hypertension in primary care $f R$ Coll Gen Pract 1980;12:6-10.

Multiple Risk Factor Intervention Trial Research Group. Multiple risk factor intervention trial: risk factor changes and mortality results. JAMA 1982;248:1465-77.

10 Miall WE. MRC retrospective morbidity survey, Rhondda Fach and Vale of Glamorgan 1954-1978. Clin Exp Hypertens 1982;4:1121-31.

11 American Heart Association. Coronary risk handbook. New York: American Heart Association, 1973.

12 Fisher CM. The ascendancy of diastolic blood pressure over systolic. Lancet 1985;ii:1349-50.

13 Gilston A. Away with diastolic pressure. Lancet 1986; ; 209.

14 Webster J. Influence of arm position on measurement of blood pressure. Br Med 7 1984;288: 1574-5.

15 Society America and Association of Life Insurance. Medical directions. Supplement of blood pressure study. New York: SAALI, 1941

16 Raftery EB. Hypertension: who and when to treat. Updale 1985;31:155-8.

17 Swales J. Comparison of intra-arterial pressures compared with cuff pressures. Journal of Hypertension 1985;3:231.

18 Sykes MK, Vickers MD. Principles of measurement for anaesthetists. Oxford: Blackwell Scientific, 1970:108-9.

19 Brunner HR, Waeben B, Nussberger J. Blood pressure recording in the ambulatory patient and evaluation of cardiovascular risk. Clin $S_{c i} 1985 ; 68: 485-8$.

20 Altman DG, Bland JM. Measurement in medicine: the analysis of method comparison studies. Statistician 1983;32:307-17.

21 Altman DG, Bland JM. Statistical methods for assessing agreement between two methods of clinical measurement. Lancet 1986; i:307-10.

22 Yelderman M, Raem AK. Indirect measurement of mean blood pressure in the anesthetised patient. Anesthesiology 1979;50:253-6.

23 Van Bergan FH. Comparison of indirect and direct methods of measuring arterial blood pressure. Circulation 1954;10:481-90.

24 World Health Organisation, 1980. Quoted by Hackett. ${ }^{6}$

(Accepted 16 fuly 1986)

\section{YEARS AGO}

A further instance of the good work done by the Smoke-Abatement Institution towards lessening one of our great social discomforts and unhealthy conditions, namely, those arising from the needless production of smoke, has been recently afforded. The Council of this Society has for some time watched with regret the failure of the smoke acts as regards steamers and tugs on the Thames, and have been in correspondence with the Home Secretary calling attention to the great and needless production of smoke on the river. A short time since, the Thompson furnace was brought to the notice of the Council; and the engineer of the institution, Mr. D. K. Clark, C.E., was instructed to make a series of scientific tests of the apparatus. His report being favourable, the Council arranged a trial trip. The tug Alexandra, fitted with the furnace, ran from Temple Pier to Richmond, lay there two hours, and then returned to Westminster. During the whole of the run, no products of combustion were visible at the top of the funnel except for about one minute each time the furnace was stoked, when a little pale smoke was emitted. After the two hours' stay at Richmond, when the fires had been allowed to get low, they were both stoked simultaneously with coal-dust, which produced smoke for nearly two minutes, but not of a dark shade. The owners of the tug, Messrs. Tough and Henderson, state that, besides the practical abolition of smoke, there is a saving of from 20 to 25 per cent. in the quantity of fuel burnt, and that inferior coal can be used. During the trip, the Richmond, the sister tug to the Alexandra, was more than once passed, burning identical coal in an ordinary furnace, and she appeared to be almost continuously emitting considerable volumes of black smoke. (British Medical foumal 1886;ii:173.)

A succession of dense local fogs, such as those which have visited the metropolis during the early part of this week, never fail to bring with them not only a number of fatalities consequent upon the difficulties attending locomotion of all kinds, but a marked addition to our mortality returns. But although the dwellers in large cities cannot escape these unpleasant visitors, they can at least, by combining, lessen somewhat their virulence. The experiments of scientists have shown that a very large part of the deleterious composition of a fog consists of the unconsumed carbon emanating from our smoky chimneys, and this baneful combination may be very greatly obviated by the use of one or other of the smokeless grates, and smokeless anthracite fuel, which the experiments carried out by Mr. C. Kennear Clark, C.E., for the National Smoke Abatement Institution, have shown to be most effectual for this purpose. The Smoke Act, which was intended to combat this evil, is, we regret to say, not administered with the stringency which the nature of the offence, and often the persistence with which it is committed, require. In 1884, in no less than 84 per cent. of the cases considered as a serious nuisance by the Commissioner of Police, no proceedings were taken, and the average fine inflicted by the magistrates in cases of conviction was only $£ 13 \mathrm{~s}$. 8d., while forty shillings is the minimum fine fixed by the Act for the first offence; no action has been taken in any case of smoke nuisance on the River Thames, where it is very prevalent. A representation made to the Home Secretary by the Smoke Abatement Institute, pointing out these facts, has met with a most unsatisfactory reply. So long as the magistrates refuse to exercise adequately the powers which the law places in their hand for this purpose, so long will it, we fear, be useless to look for any very sensible diminution of this evil. Attempts have been, and are continually made, to evade the Smoke Act, which are only frustrated by the most vigorous action on the part of the officers of the Smoke Abatement Institution. As an instance of the difficulties which this Society has successfully combated, it may be mentioned that during the time of the last elections for the present Parliament, a number of bakers banded themselves together to endeavour to obtain the exemption of that trade (which is a chief source of the nuisance) from the Smoke Nuisance Act, and certain Parliamentary candidates pledged themselves to advocate this. By giving publicity to this fact, the Institution was largely instrumental in preventing the evil. (British Medical Fournal 1886;ii:1051.)

The completion of another year's work, during which the Medical Society of London entered upon its hundred and thirteenth session, ought not to be allowed to pass without a few words of hearty appreciation. The Society has in recent years greatly enlarged its sphere of usefulness, and now fills a conspicuous place in medical life in London; it is especially the Society where men of all ranks and departments of practice can meet for exchange of opinion and experience, to the great advantage of every rank and department. Under the able and genial presidency, first of Mr. Durham, and then of Dr. W. M. Ord, its meetings have been remarkably interesting. Dr. Ord himself has contributed a very thoughtful and suggestive address on the nature of the process of fever, a subject which can never be exhausted; and he and Dr. Semon called attention to the not unfrequent occurrence of partial paralysis of the glottis-openers in locomotor ataxy, an observation as important and interesting as it was, we believe, novel. Other subjects discussed at the meetings of this Society ranged over the whole field of practical medicine. Thus Dr. Gowers read an important paper on the significance of the deep reflexes, Mr. Macpherson sketched the history of the use of ipecacuanha in dysentery, Mr. A. Pearce Gould raised an interesting discussion on the occurrence of sarcoma after injury, Mr. Treves read an elaborate paper on intussusception, and Mr. Mitchell Banks contributed a brilliant essay on the treatment of gangrenous intestine. Mr. Henry Morris's paper on the surgery of the kidney, and Professor Humphry's philosophical oration on old age and the changes incidental to it attracted wide attention. Under the auspices of Dr. Ord, also, the Society has resumed its clinical evenings, when a number of most interesting cases are collected, and afford rare opportunities for gaining a practical acquaintance with unusual forms of disease. (British Medical Foumal 1886;i:30.) 